\title{
Politeness and Its Perception by Armenian Learners of English: From Theory to Action
}

\author{
Hovhannes Vanesyan \\ Yerevan State University
}

\begin{abstract}
The study of the mechanisms of politeness in society has been a subject of interest for scholars of linguistics since the $20^{\text {th }}$ century with the development of pragmatics and sociology. The aim of the current article is to introduce the most popular politeness theories as well as investigate how linguistic politeness is understood and used by students of English. We have conducted a social survey with students of English at the Department of European languages and Communication to see how well they perceive linguistic politeness in its two forms - negative and positive - as suggested by Brown and Levinson in their seminal work "Politeness: Some Universals in Language Usage". As a result, we have arrived at some interesting conclusions with regards to the way the students understand the two types of politeness, and at the same time we have offered some ways of improving the "lacuna" in their knowledge in relation to the appropriate use of politeness in interaction.
\end{abstract}

Key words: negative politeness, positive politeness, mechanisms of politeness, politeness in society, Armenian learners of English.

\section{Introduction}

Human society leans on a myriad of pillars to ensure its harmonious existence. One of these pillars is politeness, which is expressed both verbally and non-verbally. The purpose of the current article is to introduce the theory and mechanisms behind linguistic politeness in the English language and determine how well it is understood and used by Armenian learners of English. In our work we outline the politeness theories formulated by different scholars 
of linguistics and make a distinction between negative and positive politeness as postulated by Brown and Levinson. The practical part of this article is based on a social survey conducted with the help of Yerevan State University students of the Department of European languages and Communication. Thus, we compiled a survey of 16 question-utterances of varying (im)politeness degrees and requested our respondents to match them with potential addressees (parent, sibling, teacher etc.) in order to find out how well they can distinguish between positive and negative politeness with regards to social variables from their own perspective. The survey was in form of multiple choice (more than one choice possible) printed questionnaire. We conducted the survey with 55 respondents all of whom were female within 18 to 24 age brackets.

\section{Politeness Theory}

Within the framework of politeness theory, the scholars of linguistics set apart the notion of "face", which consists of two spectrums: negative face and positive face. Brown and Levinson treat the aspects of face as "basic wants" and define the negative face as "the desire to be unimpeded in one's actions"and the positive face as "the desire (in some respects) to be approved of" (1987: 13). A speaker is expected to defend his/her own face, as well as protect that of the interlocutor's. The notion of "face" comes with its draw-backs, it is said to be culture-specific and susceptible to certain "dangers", the so-called facethreatening acts (FTA). Based on the assumption of the existence of the socalled "face" phenomenon the authors distinguish "three main strategies of politeness, 'positive politeness' (roughly, the expression of solidarity), 'negative politeness' (roughly, the expression of restraint) and 'off-record (politeness)' (roughly, the avoidance of unequivocal impositions) and claim that the uses of each are tied to social determinants, specifically the relationship between speaker and addressee and the potential offensiveness of the message content" (Brown and Levinson 1987:2). Therefore, the speaker has but two options, which are either to commit a face-threatening act or not to commit it, "if the speaker decides to do the FTA, he/she can either go off record, in which case there is more than one unambiguously attributable intention so that the speaker 
cannot have committed himself/herself to one particular intent, or the speaker can go on record expressing his/her intention clearly and unambiguously" (Trosborg 1994:26). In case of "on record" approach the speaker has two options either to express his/her utterances without redressive action, i.e. boldly on record, or use some mitigating strategies with redressive action which consists of positive and negative politeness strategies. In connection with this, Brown and Levinson propose three social determinants or social variables, as they put it "...research seems to support our claim that three sociological factors are crucial in determining the level of politeness which a speaker (S) will use to an addressee $(H)$ : these are relative power $(\mathrm{P})$ of $\mathrm{H}$ over $\mathrm{S}$, the social distance $(\mathrm{D})$ between $\mathrm{S}$ and $\mathrm{H}$, and the ranking of imposition (R) involved in doing the facethreatening act (FTA)" (Brown and Levinson 1987:15). The face-threatening act, in this case, would be, for example, an attempt to make a request, the problem would be how to phrase your request in such a way that it sounds polite according to the politeness strategies, and at the same time stays in line with the above-mentioned social factors.

Now, let's have a more concentrated look at what positive and negative "politenesses" are. Brown and Levinson state "Positive politeness is redress directed to the addressee's positive face, his perennial desire that his wants (or the actions/acquisitions/values resulting from them) should be thought of as desirable" (Brown and Levinson 1987:101). A question might arise here, what is redress? Redress can be described as a mitigating and/or accommodating action or set of strategies or according to Brown and Levinson the indication that the speaker's wants are similar to those of the addressee's and vice versa. When it comes to the linguistic realizations of positive politeness Brown and Levinson maintain that "...it is in many respects simply representative of the normal linguistic behavior between intimates, where interest and approval of each other's personality, presuppositions indicating shared wants and shared knowledge, implicit claims to reciprocity of obligations or to reflexivity of wants, etc. are routinely exchanged" (Brown and Levinson 1987:101). The similarities of positive politeness with the normal everyday "intimate behavior" is undeniable, however, there is one distinction that the authors make between 
these two; the element of "exaggeration", which they claim "serves as a marker of the face-redress aspect of positive-politeness expression, by indicating that even if S can't with total sincerity say 'I want your wants', he can at least sincerely indicate 'I want your positive face to be satisfied"' (Brown and Levinson 1987:101). The three super-strategies that make up the positive politeness strategy system are "claiming 'common ground', conveying 'that $\mathrm{S}$ and $\mathrm{H}$ are cooperators', and fulfilling 'H's want (for some $\mathrm{X}$ )'” (Brown and Levinson 1987).

Positive politeness is just one spectrum of politeness strategies that we employ in everyday life, the other one, as it was mentioned, is negative politeness. While positive politeness is meant to reduce social distance and indicate intimacy between interactants, negative politeness seeks to create that distance, indicating the social difference between the interactants.

As Brown and Levinson put it, "Negative politeness is redressive action addressed to the addressee's negative face: his want to have his freedom of action unhindered and his attention unimpeded" (Brown and Levinson 1987:129). The linguistic realization of negative politeness is effectuated with the help of the emphasis on H's relative power, hedges on the illocutionary force, conventional indirectness, polite pessimism, etc. As it was the case with the positive politeness, negative politeness too has a number of strategies that we can count on, such as being direct, trying not to assume or presume, communicating your want to not impinge on the hearer, etc. From the point of view of linguistic framing Brown and Levinson define negative politeness as achieved "with enormous syntactic complexity, a profusion of conjoined sentences and adverbial clauses..." (1987:93).

Keeping in mind the above-given definitions of politeness, especially those of its linguistic aspect in English, let us see if students of English are able to make the necessary distinction between the two types of politeness and use them appropriately. Hence, in the second part of our article, we elaborate on our findings about how well politeness is understood and used by non-native learners of English. 


\section{The Perception of Politeness by Students of English}

The phenomenon of politeness cannot exist beyond the boundaries of society and its building blocks, i.e. people, individuals. We could probably go even so far as to claim that politeness lies at the very base and is one of the supporting pillars of our civilization, one which William Golding (1954) depicts as a veil that through its rules and laws masks the evil within every individual. Hence, in order to complete our work, it is the individuals that we decided to turn to for help. We conducted a survey with students, with the help of a questionnaire made up of 16 utterances (created by us for specific situations) of varying degrees of politeness. The students were asked to match these utterances with potential addresses from among a number of options (parent, sibling, second half, boss, professor/teacher, head of department). They were specifically instructed to regard these instances as devoid of any irony or any other peculiar speaker intent, so as to ensure maximum accuracy for the research. In order to judge if the matches are correct or not we rely on common sense as well as the definitions of negative and positive linguistic politeness offered by Brown and Levinson and others as mentioned herein. The results of the survey are presented below in a bar chart. We decided to create two charts displaying both correct and incorrect picks.

\section{The Number of Correct Picks per Utterance}

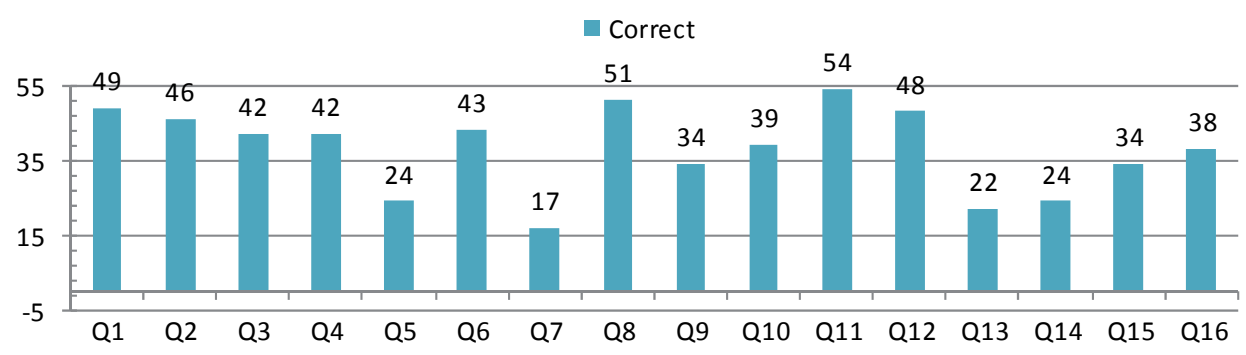

We can observe in the chart above that the respondents correctly matched most of the utterances with the addressees based on the degree and type of politeness they call for. Thus, the question "Can you tell me the time?" was matched with the addressee's parent, second half and sibling by an 
overwhelming number of respondents, which means that they could correctly identify the type of politeness and the person with whom they can use it. For example, the utterance "Can you tell me the time?" could not have been used with the head of department, or professor, since it has an extremely direct nature, it lacks the usually appropriate conventional indirectness and therefore it would be inappropriate for the respondents, all of whom are students, to use such an utterance as directed to their head of department or professor. Another, utterance "Hey, hold the door, will you?" comes in second with the number of correct matches with 51 out of 55 respondents matching it with the most likely addressees. While, utterances "I'm sorry, but I can't meet you now. I'm busy at work/University/home”, "I'm sorry, but I can't talk to you now. Call me later!" and "Hey, silly, I didn't want to make you feel bad. Look! I'm really sorry." were matched with slightly less accuracy, 49, 48, 46 respondents picking the correct addressee out of 55 respondents respectively. All of these utterances would be inappropriate and misplaced if used with address of higher status or social distance due to the reasons explained earlier. On balance, it is clearly observable that most respondents are able to easily identify the instances of positive politeness, which corresponds to everyday communication between more or less intimate interlocutors. The markers showing that these utterances belong to positive politeness are first of all special words indicating intimacy or some sort of direct or indirect closeness such as "hey", "silly", use of the imperative form of the verb without hedges "hold the door", "call me later", as well as the use of the tag question "will you", instead of a more formal "would/could you" with its respective structures. Another important marker that shows us the positive politeness nature of the above-presented utterances is the use of the modal verb "can" instead of its past form "could", which is more indirect and therefore polite (negative). And finally it is the simple structure of the utterances and their perceived casual tone that make these utterances sound more intimate, more everyday-like, and therefore more charged with positive politeness.

Leaving these results aside for the time being, now let us shift our focus onto the chart displaying the "incorrect matches", cases where the degree and 
type of the politeness of the utterance do not correspond to the addressees in terms of the social variables; relative power, distance, etc.

\section{The Number of Incorrect Picks per Utterance}

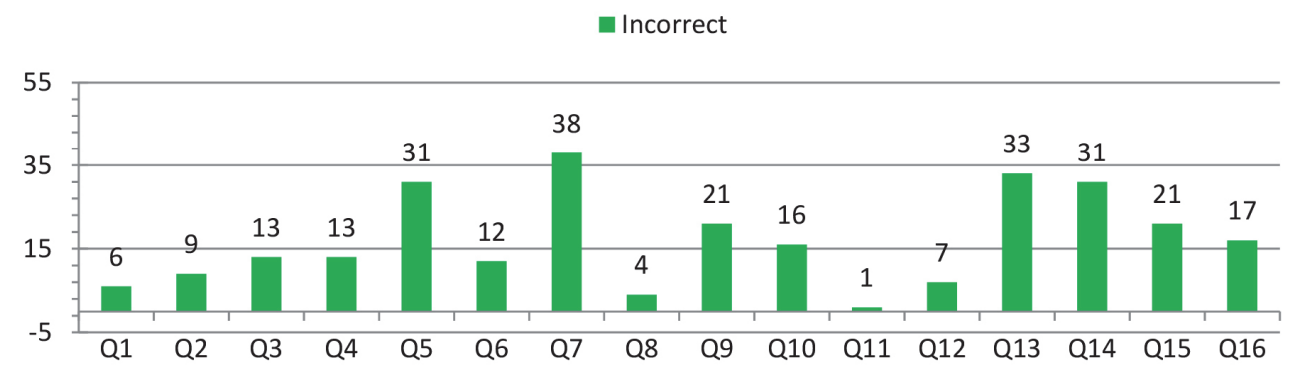

On the chart above we can pinpoint a number of mismatches that help us shed light on how our respondents perceive politeness, and how they perceive negative politeness in particular. The utterances that were mismatched with the possible range of addressees are mostly representative of (linguistically) negative politeness. Without further ado, let us consider a few mismatches that a great number of respondents (38 out of 55) failed to see for what they are. For instance, the utterance "Could you be so kind as to open the door for me? Thank you" was mismatched with such addressees as parent, sibling and second half, while in socially accepted interactions without a touch of irony or any peculiar speaker intent such an utterance would apply to an addressee whose status and social distance are higher in relation to the speaker, namely such an utterance represents (linguistically) negative politeness, which according to Brown and Levinson is achieved with enormous syntactic complexity, a profusion of conjoined sentences and adverbial clauses (1987:93). In the case of the above-introduced utterance it would be more appropriate to choose as an addressee the head of department, boss or teacher/professor; something that the respondents failed to notice. We can observe a similar mismatch for the utterances "I really appreciate your feedback but with all due respect I think you were a bit too harsh on me.", "It's very kind of you to invite me to the party 
but I have to decline it. I have a prior engagement." and "I would be happy to help you, however under current circumstances I'm unable to provide you with assistance." in all these cases the respondents picked addressees who would be unlikely to be addressed in this manner due to the existence of social variables which determine the type of politeness one should use in such interactions. The markers that set these utterances apart as negative politeness utterances are the modal verb "can" in the past form "could", which as mentioned earlier is indicative of conventional indirectness, "be so kind as to", "with all due respect", "It's very kind of you", "I'm unable to", typical phrases that are usually used in situations where the interlocutors display a high degree of mutual respect as well as such higher-level words as "decline", "assistance", "circumstances", etc. It is obvious that with regards to these utterances which represent negative politeness and display a high complexity of structure the rate of mismatch is considerably high, notably 38, 33, 31, 31 respondents out of 55 mismatched the aforementioned 4 negative politeness utterances with addressees, who are most likely to be addressed with positive politeness forms. Such utterances would be ludicrous to use with people one knows too intimately, therefore these and other similar utterances should be reserved for use in situations and with people that call for more polite conduct and comportment.

\section{Conclusion}

Overall, as a result of our research we can safely assume that most students of English have some difficulty in recognizing the instances of negative politeness, given the rate of mismatches of these utterances, and therefore they commit social blunders in the use of such utterances, whereas some of them, as indicated herein, are able to recognize and therefore correctly apply the positive politeness utterances to socially appropriate addressees. Thus, we are left with the issue of how to cultivate a deeper understanding of language and politeness mechanisms, particularly that of negative politeness in our students who formed the base of our survey. One solution that we can offer is movies, TV shows and other mass media that reflect the reality of language as it 
develops. The inclusion of such living language material in our curricula can boost the students' awareness of how the native speakers use the language in social interactions and to what norms they adhere when they apply certain linguistic expressions in speech.

\section{References:}

1. Brown, P. and Levinson, S. (1987) Politeness: Some Universals in Language Usage. Cambridge: CUP.

2. Culpeper, J. (2011) Politeness and Impoliteness. // Journal of Pragmatics. Berlin: Mouton de Gruyter.

3. Feller, S. (2009) Introduction. In the Tide of Change. In Language as Dialogue. Amsterdam: Benjamins.

4. Grice, H.P. (1975) Logic and Conversation. New York: Academic Press.

5. Lakoff, R.T. (1973) The Logic of Politeness, or Minding Your P's and Q's. Chicago: Chicago Linguistics Society 9.

6. Lakoff, R.T. (1975) Language and Women's Place. New York: Harper \& Row.

7. Lakoff, R.T. (1990)Talking Power: The Politics of Language. New York: Basic Books.

8. Leech, G. (1983) Principles of Pragmatics. New York: Longman.

9. Liu, X.g, and Allen, T.J. (2014) A Study of Linguistic Politeness in Japanese. Sydney: Published Online in SciRes.

10. Locher, M.A. (2012) Politeness Research from Past to Future, with a Special Focus on the Discursive Approach. UK: Cambridge Scholars Publishing.

11. Trosborg, A. (1995) Interlanguage Pragmatics. Berlin: Mouton de Gruyter.

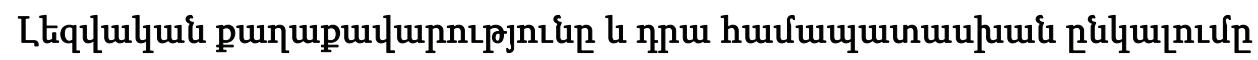

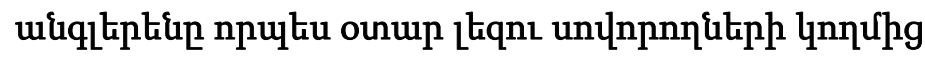

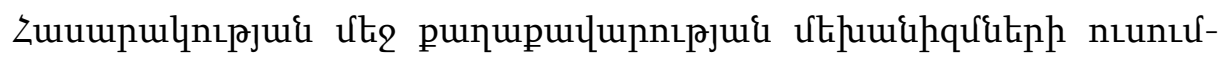

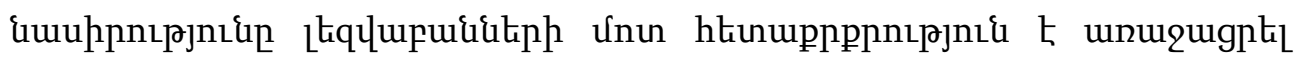




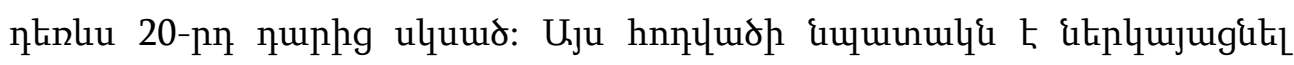

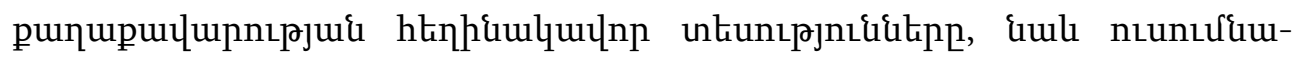

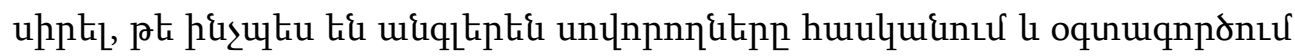

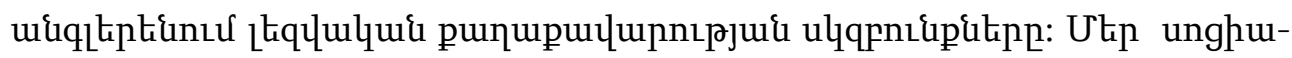

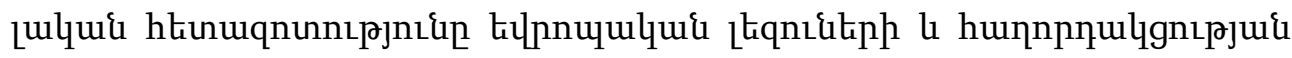

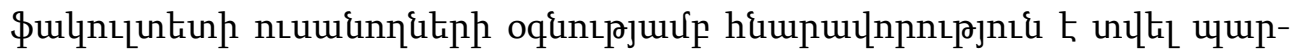

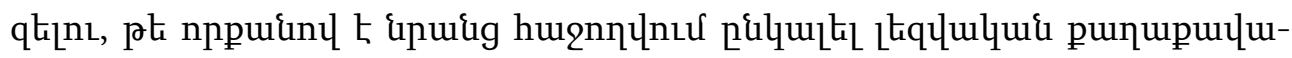

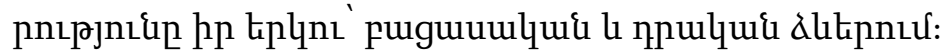

Received by the Editorial Board 21.12.2018

Recommended for publication by the reviewers 20.02.2019

Accepted for print 22.04.2019 